\title{
Integrating MOOCs with Traditional Classroom Instruction to Improve Teaching Effectiveness
}

\author{
Xiaodong Wu, Yuzhu Zeng \\ Faculty of Mathematics and Computer Science, Quanzhou Normal University \\ Fujian Provincial Key Laboratory of Data Intensive Computing \\ Key Laboratory of Intelligent Computing and Information Processing, Fujian Province University \\ Quanzhou, China
}

\begin{abstract}
Massive Open Online Course (MOOC) is a new teaching mode appeared in recent years and its emergence has constituted some challenge to the traditional teaching. However, MOOCs teaching mode has both advantages and disadvantages. In this paper, both the merits and the demerits of MOOC education are analyzed. We point out that the MOOC education mode and the traditional face-to-face classroom instruction should be combined together so as to improve the teaching effectiveness in modern education. Finally, how to blend the MOOC mode and the traditional classroom teaching and further utilize the network platform to improve the teaching efficiency in several learning phases are examined.
\end{abstract}

Keywords-MOOCs; face-to-face teaching; traditional teaching; network teaching platform

\section{INTRODUCTION}

In recent years, Massive Open Online Course (MOOC) has been developing rapidly and has received widespread attention of all social circles. "MOOCs" represents open access, global, free, video-based instructional contents, videos, problem sets as well as forums released through an online platform to high volume participants who intent to take a course or to be educated [1].

Currently, MOOCs are playing an important role in education. Since it is open access, free, and the learners are able to arrange their study time flexibly such that they can organize themselves better, a substantial amount of people have joined the rank of MOOCs learning. Among the MOOCs providers, Udacity, Courseera, edX, Open2Study, and FutureLearn are acknowledged as the most popular [2].

In 2012, more than 155,000 students registered for "Circuits and Electronics" (6.002x), which is the first MOOC course developed by edX [3]. In the same year, over 100,0000 people participated in the three most influential MOOCs platforms, i.e., Coursera, Udacity and edX, to learn free online courses. The year 2012, therefore, was branded "The Year of the MOOC” by the New York Times [4].

Although MOOCs education has got a rapid development and attained a degree of recognition over the past few years, numerous challenges still remain such as doubt on its quality and creditability, the contradiction between high student attrition rate and low active participation, and so on. In this paper, we suggest that the MOOCs should be combined with the traditional face-to-face classroom teaching in the higher education, and the MOOCs platform should be fully utilized to help enhance the teaching efficiency, so as to make the most of the advantages of these two teaching mode.

\section{Advantages And Disadvantages of MoOcs}

The concept of MOOC was firstly brought forward by Canadian academic when the class "Connectivism and Connective Knowledge” was created by Stephen Downes and George Siemens at the University of Manitoba in 2008 [5]. They designed this course utilizing the philosophy of "MOOC" Different kinds of platforms were applied in this course, including blogs, forums, Facebook groups and other resources, to help students with the course studying. The course was offered for free and approximately 2300 students registered for this course.

Over the next several years, MOOCs gained more attention in America, the most powerful country in education. Many world-class universities, such as Stanford University, Massachusetts Institute of Technology (MIT), and Princeton University began to contribute their MOOC courses and explore this kind of new teaching model.

In 2012, several companies dedicated to promoting MOOCs cooperate with the world's leading academic institutions, and establish global massive open online course learning platforms like Coursera, Edx and Udacit.

According to a report issued by Stanford Class Central, more than 550 universities offer over 4200 MOOC courses [6], among which 1800 new courses were announced just in the year 2015. As can be seen from figure 1, MOOCs get unparalleled development in the past two years. 
Growth of MOOCs

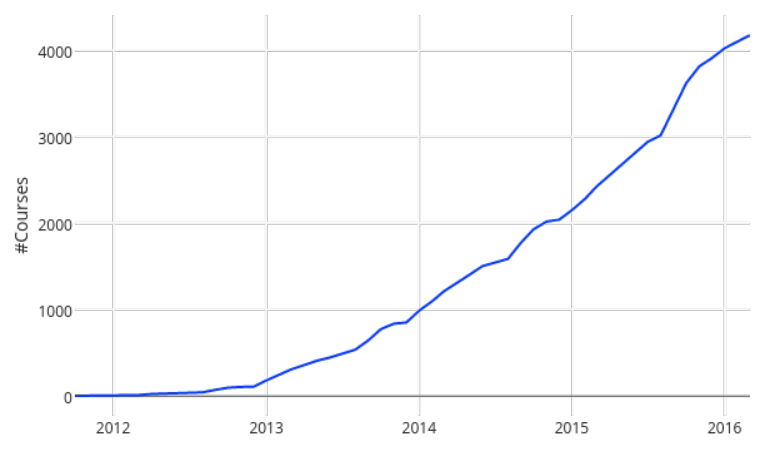

Fig. 1. The growth of MOOC courses in recent years. [7]

The concept of MOOCs is to provide educational resources for a big number of people around the world, such that they are able to get opportunities to study college and university courses through the access to the internet [8]. Compared with the traditional face-to-face class, MOOCs has many special characteristics and advantages such as free courses offered by top tier universities, short instructional videos, and low costs to possess MOOCs [9].

\section{A. Advantages}

\section{1) Low Learning Cost}

Unlike other traditional online courses, the MOOC courses are usually free or at very low cost and open to anyone with Internet access. Consequently, MOOCs is capable of expanding the higher educational opportunities for the public beyond colleges and universities, as long as they have an Internet connection. Especially those who could not have the chance to enter the university campus now can conveniently study the university courses through a MOOC platform at a low cost or even for free.

Although the cost of the MOOC curriculum building is usually higher than that of traditional teaching, the cost of organization and implementation of MOOCs are relative low. As a result, the MOOCs educational mode can obtain a high return rate of investment.

\section{2) Sharing And Openness}

As the MOOC courses are often offered by top universities such as Stanford, Massachusetts Institute of Technology and Harvard, which offers vast number of students opportunities to learn from the most distinguished professors in the world. Further, the openness of MOOCs will help stimulate the development of the internationalization of higher education and promote the sharing of the global high-quality educational resources.

\section{3) Efficient Technical Management}

After a long time using of the MOOC platform, massive amounts of data will be accumulated and those data can be used for further analyzing and mining. For example, Harvard and MIT developed an open source Python package to analysis and process large amount of course data from edX, in which Google BigQuery is used to process multiple terabytes of learning data [10].

In addition, through the analysis and learning of the historic learner data, the platform will be able to give suggestions about how to adjust the studying plan and learning method so as to enhance the efficiency of students' learning.

In the area of traditional engineer education, one of the main obstacles is the lack of good and latest experimental equipment since it usually costs an astronomical sum of fund. With the help of modern information technology, the Virtual Lab project [11] addresses this problem by adopt the remote experimentation. More than 10000 learners have performed the online experiments under the Virtual Labs project [11].

\section{B. Disadvantages}

MOOCs have some distinct advantages and have even brought a huge impact on the traditional education all over the world. However, MOOCs also has its disadvantages.

In terms of costs, it may be free for students to use the learning materials from MOOCs platform. Nevertheless, in some developing countries such as China, the network infrastructure is relatively backward (the network bandwidth speed in China ranked $118^{\text {th }}$ all over the world) [ 12 ]. Meanwhile, the higher Internet access fees increase the cost of online learning, which may become an obstacle of the popularity of MOOCs education.

Moreover, according to [13], the concept of offering free courses may be reversed in the near future.

For college students, credit transferability is another barrier since colleges and universities are inclined not to accept MOOC courses from other institutions unless they are associated with their own programs [14].

One more trouble aspects of MOOCs is the low completion rate [3] although there are a particularly large number of participants. The average rate is no more than $10 \%$. Even the completion rate of $6.002 x$ (the course "Circuits and Electronics” developed by edX) is less than 5\%. Figure 2 illustrates the stop out rate curve for students throughout the 14 weeks of the course 6.002x. [3]

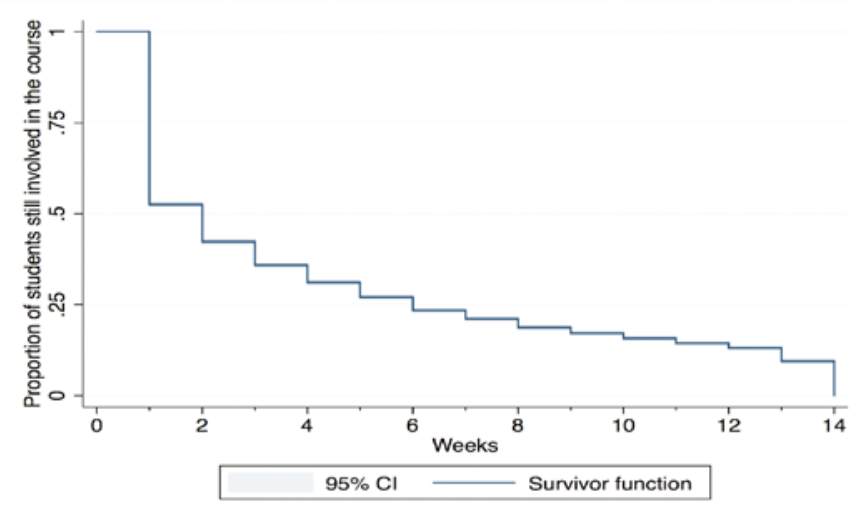

Fig. 2. Stop out rate of students throughout 6.002x. [3] 
The MOOC platform usually provides students with forums for studying discussion and communication. However, according to the research of [3], only $3 \%$ of the students join in the discussion on average.

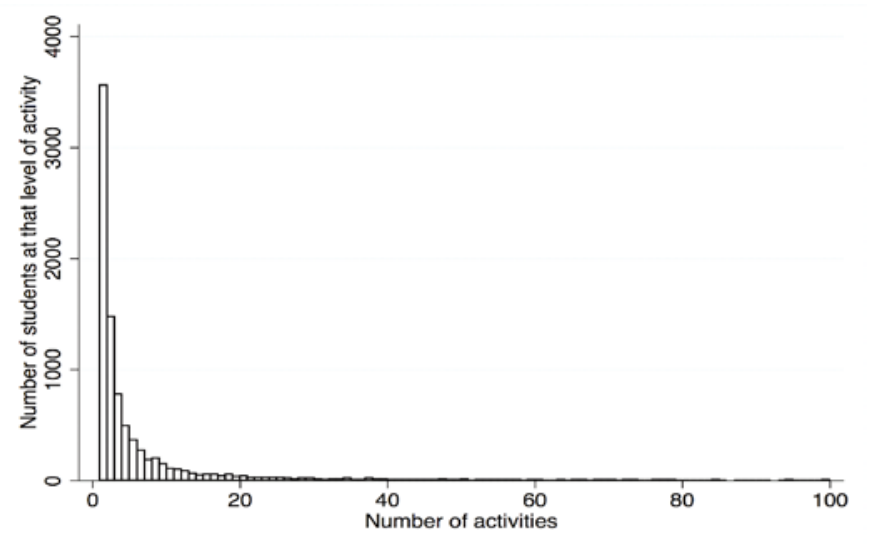

Fig. 3. Distribution of discussion board activity for students with 100 posts or less. [3]

In addition, there are other weakness in MOOC teaching, such as abundance of cheating and plagiarism, and possible superficial education. Conversely, these phenomena are unlikely to appear in a traditional college classroom. In the process of studying MOOC lectures, there is a lack of interaction between students and teachers or students and students, which is exactly the natural property of traditional face-to-face instruction. Therefore, we argue that in colleges and universities, the MOOC teaching mode should be regarded as a supplementary means of classroom instruction. These two means should be combined together so as to improve the teaching efficiency and effectiveness

\section{BLENDING MOOCs WITH FACE-TO-FACE INSTRUCTION}

In this section, we suggest that the MOOC and the traditional teaching mode should be integrated together to achieve better results. How to combine the two in several links of instructional procedure is also analyzed.

The study of a course can usually be divided into five stages, that is, preparing for the lesson, attending class, reviewing the lesson, doing homework, and course examination/evaluation. We will examine how to apply the blended approach to these stages so that the efficiency can be increased.

The goal of preview is to figure out what to learn in the class and find out the difficult points, so as to improve the learning efficiency of class. In this stage, teachers can upload the materials that should be previewed by students onto the MOOC platform before class, such that the platform can be utilized to help students to know about the main topics of the course. The materials may be in the form of documents, PPTs, videos, audios or forum posts. Each student should identify what is the emphasis and difficulty to him/her, such that he/she could concentrate on key points to improve learning effectiveness. Learners are the principal part of this stage, as seen in Figure 4.

Classroom teaching is the central part of college study. In this stage, the traditional face-to-face instruction should be applied as the main method to achieve better interactive. Students can ask questions and both the teacher and students can join in the discussion in the classroom. However, since the classroom teaching is usually dominated by the teachers' explanation, the leading role of the classroom teaching should be the instructor.
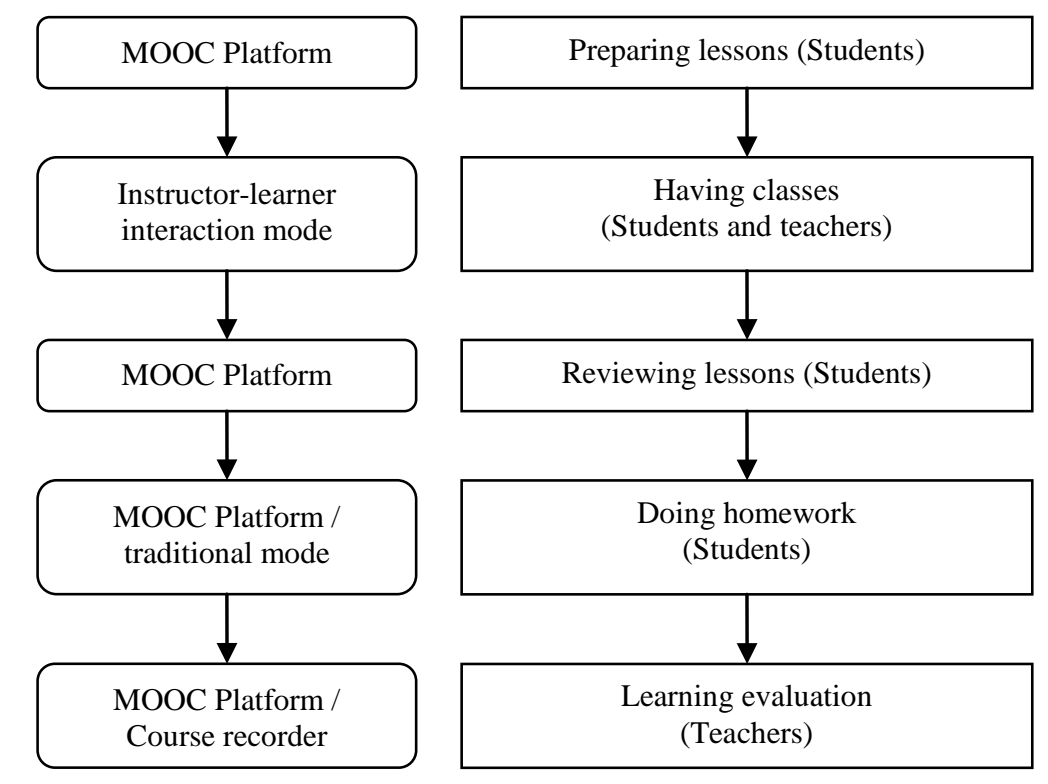

Fig. 4. The five important phase and the corresponding methods and means of giving a course: preparation, taking class, review, homework and evaluation.

Another important link of learning is reviewing. The goal of reviewing includes consolidating learning, making up for deficiency, deepening students' understanding, improving their ability of knowledge application and so on. In time reviewing 
can effectively consolidate the key knowledge points and reduce forgotten. Similarly, the MOOC platform can be utilized to improve the efficiency of the review by uploading and sharing the reviewing materials onto the network platform.

Some network learning platforms have already provided the functionality to submit homework through the network so as to reduce paper wastage. Therefore, both the MOOCs system and the traditional mode (e.g., handwriting task) can be adopted in this stage.

Finally, in the evaluation stage, teachers usually give the final performance according to several aspects such as performance in class, quizzes, assignments, final exam and so on. Note that some learning historical data have already been stored in the MOOC system. Moreover, the examination can be conducted online on the MOOC platform. Hence, the MOOC platform and the teaching log should be combined together to comprehensively evaluate the students' study.

In sum, the combination of MOOCs platform and face-toface classroom instruction can efficiently help the teachers and the students to complete a course.

\section{CONCLUSION}

MOOCs teaching mode has both advantages and disadvantages. In this paper, the merits and demerits are analyzed. Either using only the traditional method or MOOCs teaching has shortcomings. Therefore, we pointed out that the MOOCs mode and the traditional face-to-face instruction should be combined together in modern education. Moreover, how to blend the MOOC mode and the classroom teaching as well as utilize the network platform in several learning phases are examined, so as to improve teaching quality and studying efficiency.

\section{ACKNOWLEDGMENT}

This work is supported in part by the Natural Science Foundation of Fujian Province, China (Grant No. 2015J01663), by the Key Project of Quanzhou City Science and Technology Program (No.2015Z121, 2014Z134), by the 13th five-year planning project of Fujian education science (FJJKCG16-366), and by the Quanzhou Normal University Scientific Research Initiative Foundation.

\section{REFERENCES}

[1] Baturay, Meltem Huri. "An Overview of the World of MOOCs." Procedia - Social and Behavioral Sciences 174.1(2015):427-433.

[2] Aracele Garcia de Oliveira Fassbinder, Marcelo Fassbinder, Ellen Francine Barbosa, "From flipped classroom theory to the personalized design of learning experiences in MOOCs", 2015 IEEE Frontiers in Education Conference (FIE), vol. 00, no. , pp. 1-8, 2015, doi:10.1109/FIE.2015.7344146

[3] Breslow, Lori, et al. "Studying Learning in the Worldwide Classroom Research into edX's First MOOC. " Research \& Practice in Assessment 8(2013):13-25.

[4] Wang, Wei Ping, P. Wang, and L. I. Si-Yuan. "The Dilemma of Current MOOC Development.". 2016 3rd International Conference on Social Science (ICSS 2016).

[5] Sanchez-Gordon, Sandra, and S. Luján-Mora. "MOOCs Gone Wild." International Technology, Education and Development Conference 2014.

[6] Aydin, Cengiz Hakan. "Current Status of the MOOC Movement in the World and Reaction of the Turkish Higher Education Institutions." Open Praxis 9.1(2017):pages. 59-78.

[7] Shah, D. "Less Experimentation, More Iteration: A Review of MOOC Stats and Trends in 2015." Retrieved from https://www.classcentral.com/report/moocs-stats-and-trends-2015 (2016, May 13).

[8] Lecounte, J. F., and D. D. Johnson. "The MOOCs: Characteristics, benefits, and challenges to both industry and higher education." 282.5(2015):951-962.

[9] Daniel, Sir John. "Making Sense of MOOCs: Musings in a Maze of Myth, Paradox and Possibility." Journal of Interactive Media in Education 2012.3(2013):18.

[10] Lopez, Glenn, et al. "Google BigQuery for Education: Framework for Parsing and Analyzing edX MOOC Data." Proceedings of the Fourth (2017) ACM Conference on Learning @ Scale ACM, 2017:181-184.

[11] Bose, Ranjan. "Virtual Labs Project: A Paradigm Shift in Internet-Based Remote Experimentation." IEEE Access 1(2013):718-725.

[12] Huan Cheng-lin, and Chen Jian-wei, "SWOT Analysis on the Development of MOOC in China's Higher Education." American Journal of Educational Research, vol. 4, no. 6 (2016): 488-490. doi: 10.12691/education-4-6-8.

[13] Lecounte, J. F., and D. D. Johnson. "The MOOCs: Characteristics, benefits, and challenges to both industry and higher education." 282.5(2015):951-962.

[14] Kolowich, S. "The Minds Behind the MOOCs The Professors Who Make the MOOCs.” The Chronicle of Higher Education. 